\title{
DOE/ER/ $60721--12$
}

April 10, 1995

FINAL REPORT

FOR THE U.S. DEPARTMENT OF ENERGY

GRANT NUMBER DE-FG05-88ER60721

Project period: $11 / 01 / 91$ to $03 / 31 / 95$

RECEIVED

JAN $O 71997$

OSTI

QUASI-ELASTIC NEUTRON SCATTERING STUDIES OF PROTEIN DYNAMICS

Huey W. Huang

Department of Physics

Rice University

Houston, Texas 77251 


\section{DISCLAMMER}

Portions of this document may be illegible in electronic image products. Images are produced from the best available original document. 


\section{DISCLAMMER}

This report was prepared as an account of work sponsored by an agency of the United States Government. Neither the United States Government nor any agency thereof, nor any of their employees, makes any warranty, express or implied, or assumes any legal liability or responsibility for the accuracy, completeness, or usefulness of any information, apparatus, product, or process disclosed, or represents that its use would not infringe privately owned rights. Reference herein to any specific commercial product, process, or service by trade name, trademark, manufacturer, or otherwise does not necessarily constitute or imply its endorsement, recommendation, or favoring by the United States Government or any agency thereof. The views and opinions of authors expressed herein do not necessarily state or reflect those of the United States Government or any agency thereof. 


\section{Introduction}

This project was originally initiated by late $\mathrm{H}$. E. Rorschach. At the time of his untimely death in the summer of 1993, the major portion of the proposed experiments were done. I took over the project on November 1, 1993. I finished the remaining experiments and completed the data analysis. In the following report I will give a brief summary of this project and describe in some details the major results. The complete technical report is contained in the $\mathrm{Ph}$. $\mathrm{D}$. thesis of Hung Cao (Rice University, May 1995).

Proteins are formed from long polymer chains of amino acids that have been cross linked into a complex three dimensional structure. The structure is not unique, since there are many conformation substates of nearly equal energy, separated by small energy barriers, that are obtained by slight shifts in positions of various segments of the molecule. Transitions among these conformations substates are of a diffusive nature, and they can lead to substantial changes in the shape of the molecule. These changes in shape are important for the biological reactions in the cell. Such diffusive motion is inaccessible to the diffraction methods or to the computer simulations, since it occurs on a long time scale. It is accessible to incoherent quasi-elastic neutron scattering (IQNS) studies, which permit a direct determination of the properties of the diffusive motion of the protons in the molecules.

We have used the IQNS method to study the motions of the side chains in trypsin, a protein of beta-sheet structures and myoglobin, a protein of $\alpha$-helical structures, at various $\mathrm{D}_{2} \mathrm{O}$ hydration levels. The scattering spectra $\mathrm{S}(\mathrm{Q}, \omega)$ were measured in constant $\mathrm{Q}$-mode. The proteins in powder form exhibits vibrational high-frequency motions, whereas the proteins in solution and in crystal are characterized by diffusive jumps and high-frequency vibrations. At temperatures below $200 \mathrm{~K}$, $\mathrm{S}(\mathrm{Q}, \omega)$ for these proteins in solution is similar to an harmonic solid. As temperature increases, a transition is seen at $200 \mathrm{~K}$, above which the proteins become more liquid-like with rapid transitions between conformation substates. The diffusion constant $\mathrm{D}$ for the side chains is on the order of $10^{-6} \mathrm{~cm}^{2} / \mathrm{sec}$.

\section{Experimental Method}

\section{Theoretical basis}

Consider an incoherent scattering of a system described by a self-correlation function $\mathrm{G}_{\mathrm{s}}(\mathbf{r}, \mathrm{t})=\mathrm{N}^{-1}<\Sigma_{\mathrm{i}} \int \mathrm{d} \mathbf{r}^{\prime} \delta\left(\mathbf{r}+\mathbf{r}_{\mathrm{i}}(0)-\mathbf{r}^{\prime}\right) \delta\left(\mathbf{r}^{\prime}-\mathbf{r}_{\mathrm{i}}(\mathrm{t})\right)>$, where $\Sigma_{\mathrm{i}}$ sums over the hydrogen atoms in the system. IQNS measures $S_{\text {inc }}(Q, \omega)$ which is defined as the time-space Fourier transform of $\mathrm{G}_{\mathrm{s}}(r, \mathrm{t})$. Note that the measured intensity, however, is the integration of $S_{\text {inc }}(Q, \omega)$ over an energy interval equivalent to the energy resolution $\Delta \omega$. If the scattering particles are able to diffuse freely 
throughout the whole sample volume $\mathrm{V}$, then, as $\mathrm{t}->\infty, \mathrm{G}_{\mathrm{s}}(\mathbf{r}, \infty)=\mathrm{N}^{-1} \Sigma_{\mathrm{i}} \int \mathrm{d} \mathbf{r}^{\prime}<\delta\left(\mathbf{r}+\mathrm{r}_{\mathrm{i}}(0)-\mathbf{r}^{\prime}\right)><\delta\left(\mathbf{r}^{\prime}-\right.$ $\left.\mathbf{r}_{\mathrm{i}}(\infty)\right)>\sim 1 / \mathrm{V} \sim 0$. On the other hand, if the motion of the particle is restricted to a finite region. Then $\mathrm{G}_{\mathrm{s}}(r, \infty)$ is finite. The scattering spectrum separates into two parts:

an elastic peak, $S_{\text {inc }}{ }^{\mathrm{el}}(\mathrm{Q}, \omega)=\delta(\omega) \int \mathrm{dre}^{\mathrm{ik} \cdot \mathbf{r}} \mathrm{G}_{\mathrm{s}}(\mathbf{r}, \infty)$ and

an inelastic band, $S_{\text {inc }}{ }^{\text {inel }}(Q, \omega)=\int d \mathbf{r d t e}{ }^{i k \cdot r-i \omega t}\left[G_{s}(\mathbf{r}, t)-G_{s}(r, \infty)\right]$.

\section{Instrument}

Our experiment was carried out at the Brookhaven National Laboratory using the H9A triple-axis spectrometer, which is one of the cold neutron facilities. To increase the beam intensity of low energy neutrons ( $<5 \mathrm{mev}$ ), a liquid hydrogen moderator system was installed in the beam thimble. This shifted the spectral distribution of the emerging beam towards lower energies. A triple axis spectrometer was used to measure the energies of the incident and scattered neutrons. The energy resolution $\Delta \omega$ was about $10^{-4} \mathrm{ev}$. That means that if the system does not relax to equilibrium within $4 \times 10^{-11} \mathrm{~s}$, there won't be an elastic peak. We had to bear this limitation in mind when we analyzed our data.

\section{Experimental Results}

1. Protein powder: trypsin and myoglobin powders were lyophilized, freeze-dried in $\mathrm{D}_{2} \mathrm{O}$ to exchange loosely bound hydrogens on the protein with about $0.086 \mathrm{~g}$ of $\mathrm{D}_{2} \mathrm{O}$ per gram of protein. Fig. 1 shows a typical scattering IQNS spectrum of protein powder. The analysis of these spectra indicates that the scattering is purely elastic with no detectable quasi-elastic line. The data can be fit with a Debye-Waller factor $\exp \left(-\mathrm{Q}^{2}<\Delta \mathrm{X}^{2}>\right)$. For protein powder at $320 \mathrm{~K}$ the mean square displacement is $\left\langle\Delta \mathrm{X}^{2}\right\rangle=0.139 \pm .007 \AA^{2}$.

\section{Protein in solution:}

(a) $\mathrm{T}<200 \mathrm{~K}$. The scattering cross section of trypsin and myoglobin in solution between $100-200 \mathrm{~K}$ exhibit characteristics similar to protein powder (Fig. 2), i.e., the scattering consists of only an elastic peak. The fitting showed that $\left\langle\Delta X^{2}>\right.$ are $0.055 \AA^{2}, 0.06 \AA^{2}$, and $0.072 \AA^{2}$, for $100 \mathrm{~K}$, $150 \mathrm{~K}$, and $200 \mathrm{~K}$ respectively.

(b) $280 \mathrm{~K}$ and $300 \mathrm{~K}$. Figs. 3 and 4 show the results for $280 \mathrm{~K}$ and $300 \mathrm{~K}$. Each spectra was fitted with a Lorentian. (The resolution is not good enough to fit the spectra with an elastic peak and a Lorentian.) The linewidths increase and level off at large values of Q (Fig. 5). This characteristic is common for jump diffusion models. Fig. 5 shows that the data can be fit with a jump diffusion model with a gaussian jump-length distribution. 
3. Protein in crystal: The analysis of crystal data is more difficult than we had originally anticipated. Fig. 6 shows a typical crystal spectrum. We had two problems with this spectrum. The first is the absence of an elastic peak. The second is not knowing the exact amount of exchangeable $\mathrm{D}_{2} \mathrm{O}$ in the crystals. These problems make a meaningful interpretation of the crystal data difficult.

\section{CONCLUSIONS}

The neutron scattering technique can be used to study motions in biological molecules with relaxation times as long as $10^{-8} \mathrm{~s}$. This unique capability fills the time gap between the current limitations of molecular dynamic simulations (about $10^{-10} \mathrm{~s}$ ) and NMR techniques (about $10^{-8} \mathrm{~s}$ ). However the detection of relaxation time $10^{-8} \mathrm{~s}$ requires the energy resolution of the diffractometer to be of the order of $5 \times 10^{-7} \mathrm{ev}$. Currently only the 90 degree-spectrometer in the Institut LaueLangevin in Grenoble, France has this capability. The triple axis diffractometer we used in the Brookhaven National Laboratory has a resolution $10^{-4} \mathrm{ev}$, which could only resolve relaxation times shorter than $4 \times 10^{-11}$ s. Nevertheless, we have obtained some important results concerning the internal motions of proteins.

From the elastic peaks of proteins in powder and in solution, the proteins' hydrogens exhibit high frequency vibrations, which can be modeled by the harmonic Debye-Waller factor $\exp \left(-\mathrm{Q}^{2}<\Delta \mathrm{X}^{2}>\right)$. The mean-square displacement $<\Delta \mathrm{X}^{2}>$ shows an interesting dependence on temperature. Below $200 \mathrm{~K},\left\langle\Delta X^{2}>\right.$ increases with temperature with a constant slope, as expected for harmonic vibrations. Above $200 \mathrm{~K},\left\langle\Delta \mathrm{X}^{2}>\right.$ also increases with temperature with a constant slope, but the slope is distinctly higher than the low temperature one (Fig. 7). This anomalous behavior has been termed a glass transition. The same phenomenon has now also been found in simple liquids, and chain polymers.

The motion of hydrogen atoms in proteins both in solution and in crystal can be described by a jump-diffusion model as indicated by the Q-dependence of the linewidths. The selfcorrelation function $G_{S}(r, t)$ of a diffusion problem can be solved analytically. There are two limiting cases, depending on the scale of the observation time. For times much longer than the interval $\tau$ between two jumps (corresponding to small Q's), the translational motion is described by a continuous diffusion, where the self-diffusion coefficient $\mathrm{D}$ is defined by linewidth $=\mathrm{DQ}^{2}$. For short times (corresponding to large $Q$ 's), the characteristics of jump steps dominate. The linewidth approaches an asymptotic value $1 / \tau$.

The neutron results are independent of the secondary structure of protein. Myoglobin is primarily $\alpha$ helical, whereas trypsin primarily $\beta$ sheets. Yet the motions of the side chains in them are almost indistinguishable. 


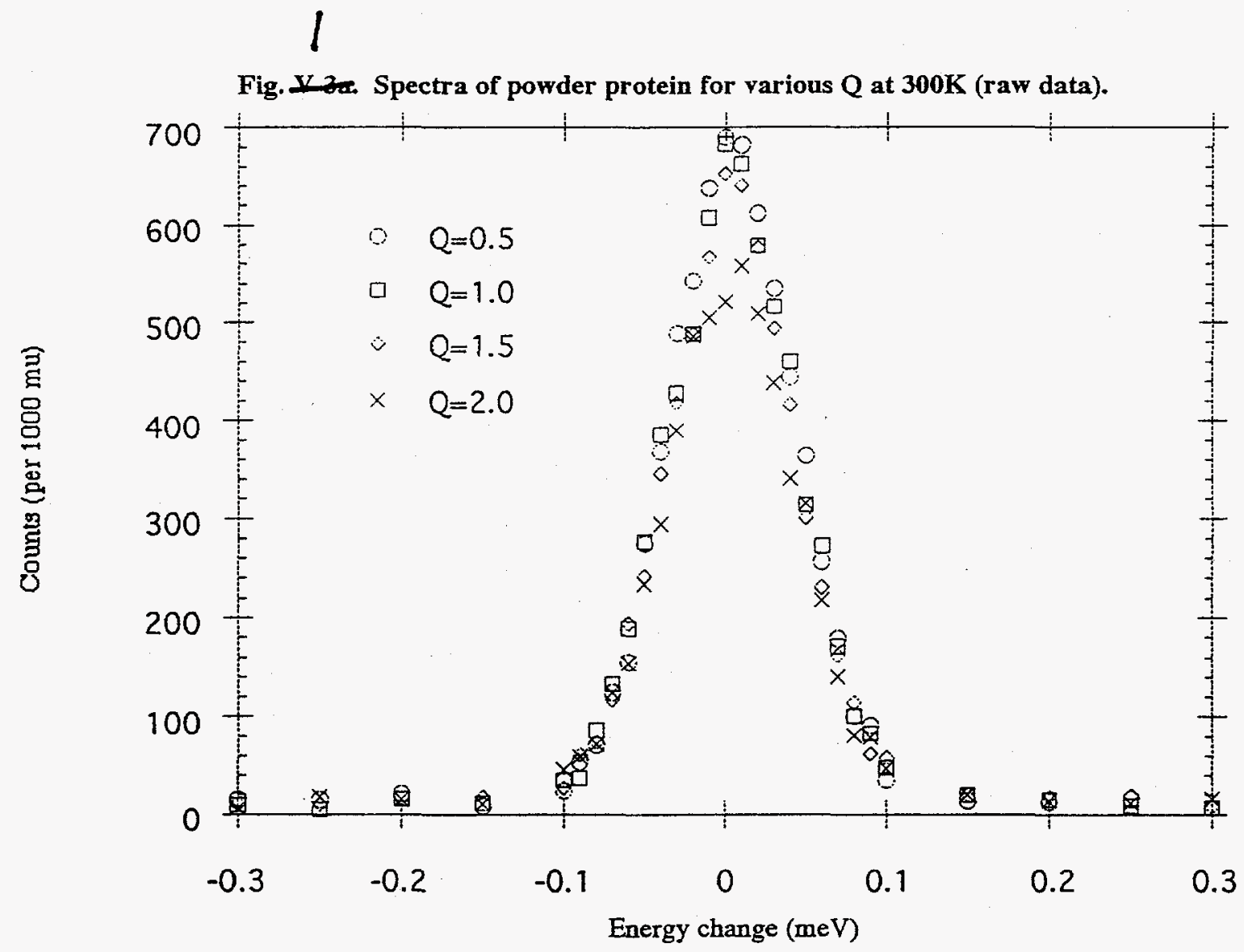


2

Fig. Spectra of trypsin-solution for various $Q$ at $200 \mathrm{~K}$ (raw data).

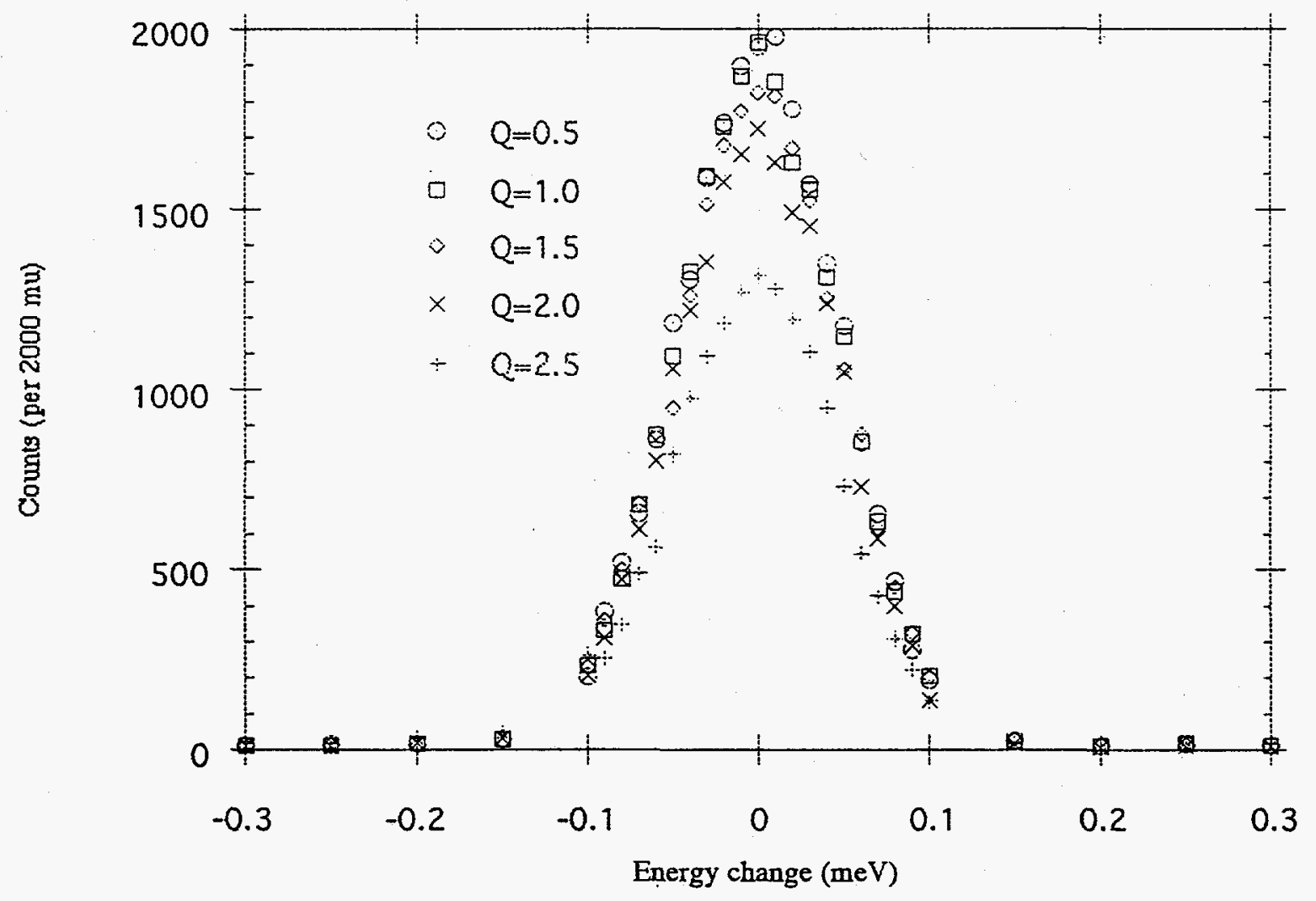


3

Fig. Spectra of myoglobin-solution for various $Q$ at $280 \mathrm{~K}$ (raw data).

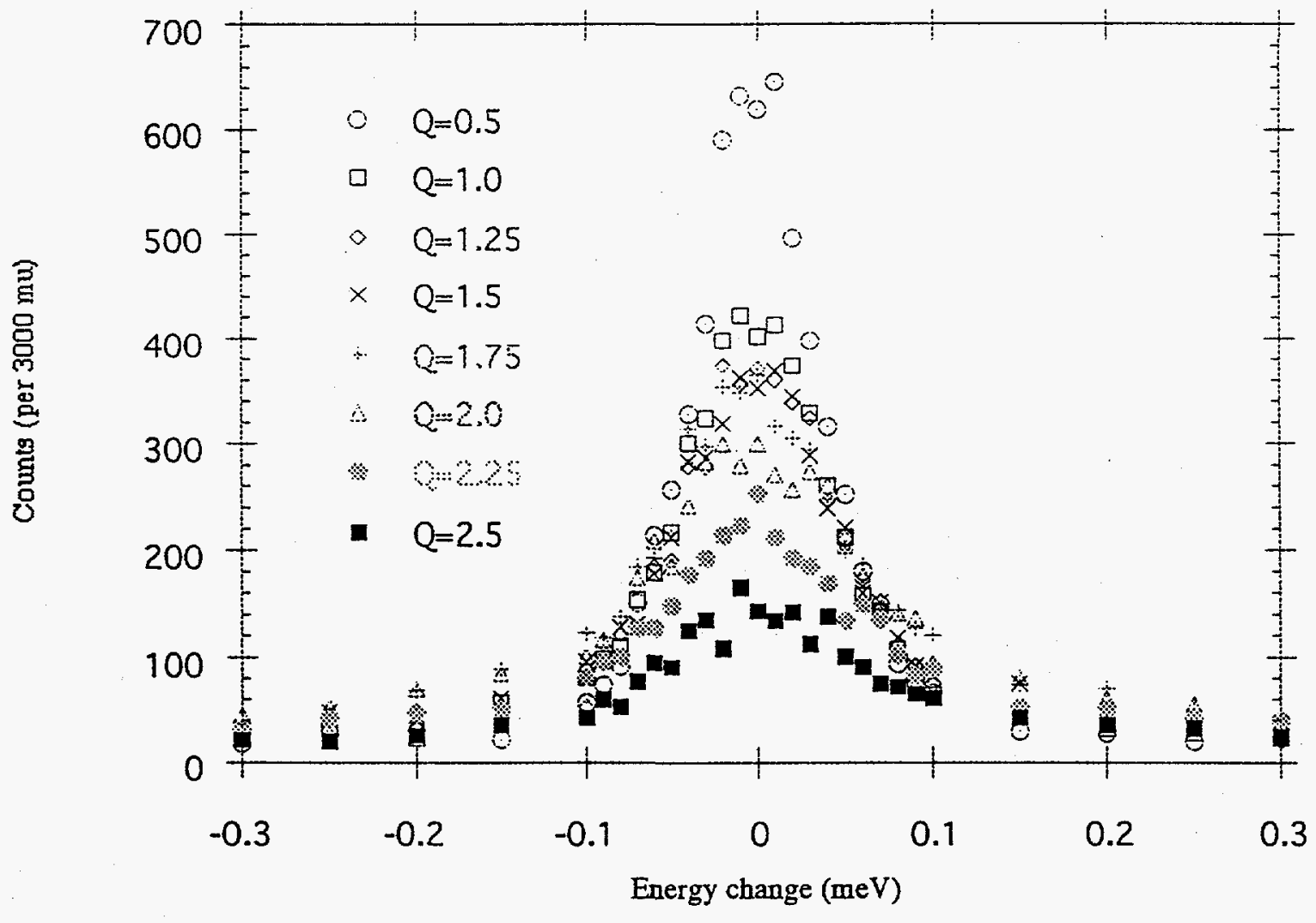




\section{4}

Fig. Spectra of myoglobin-solution at various $Q$ at $300 \mathrm{~K}$ (raw data).

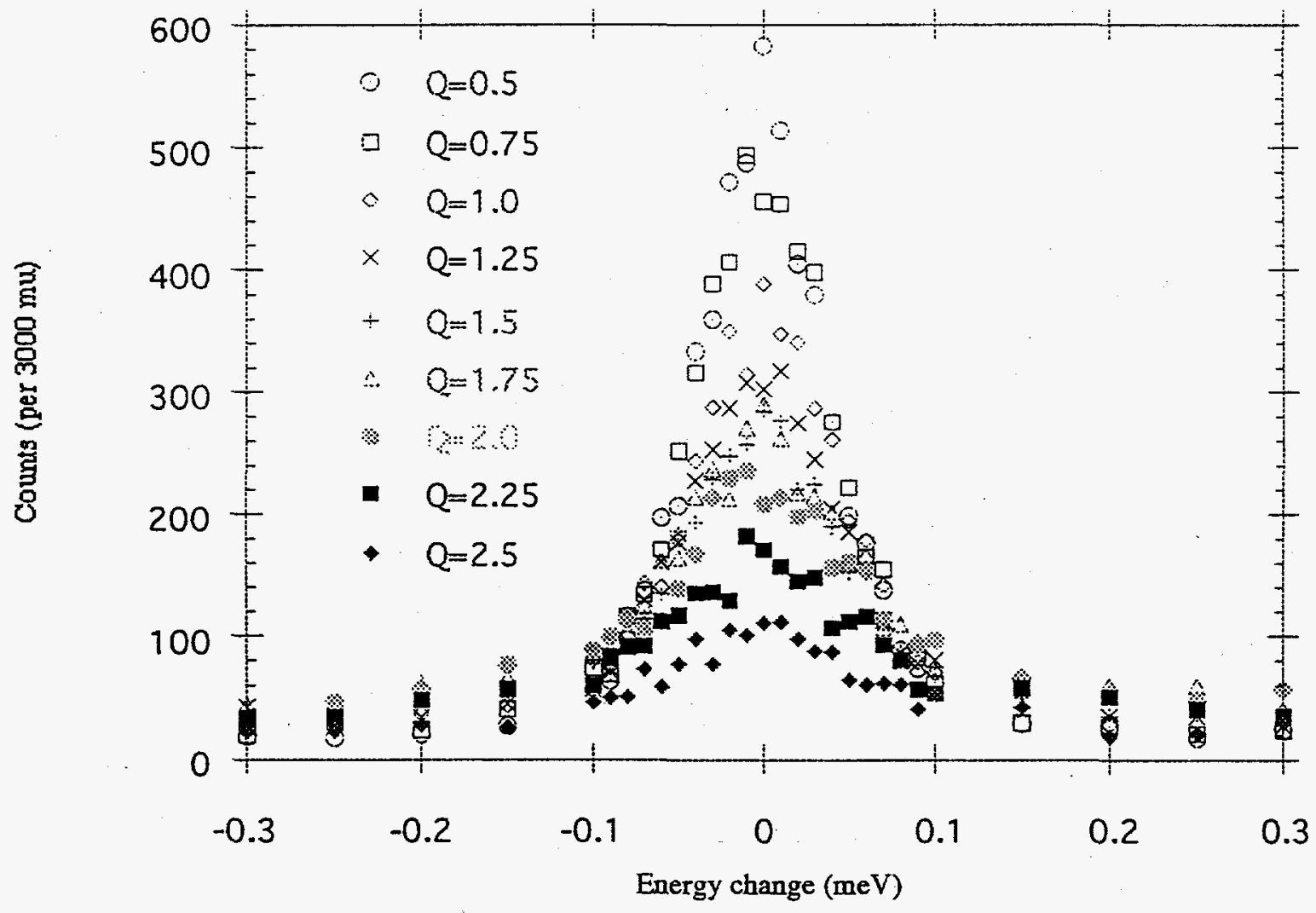




\section{5}

Fig. 16 Byoglobin-solution at 280K.

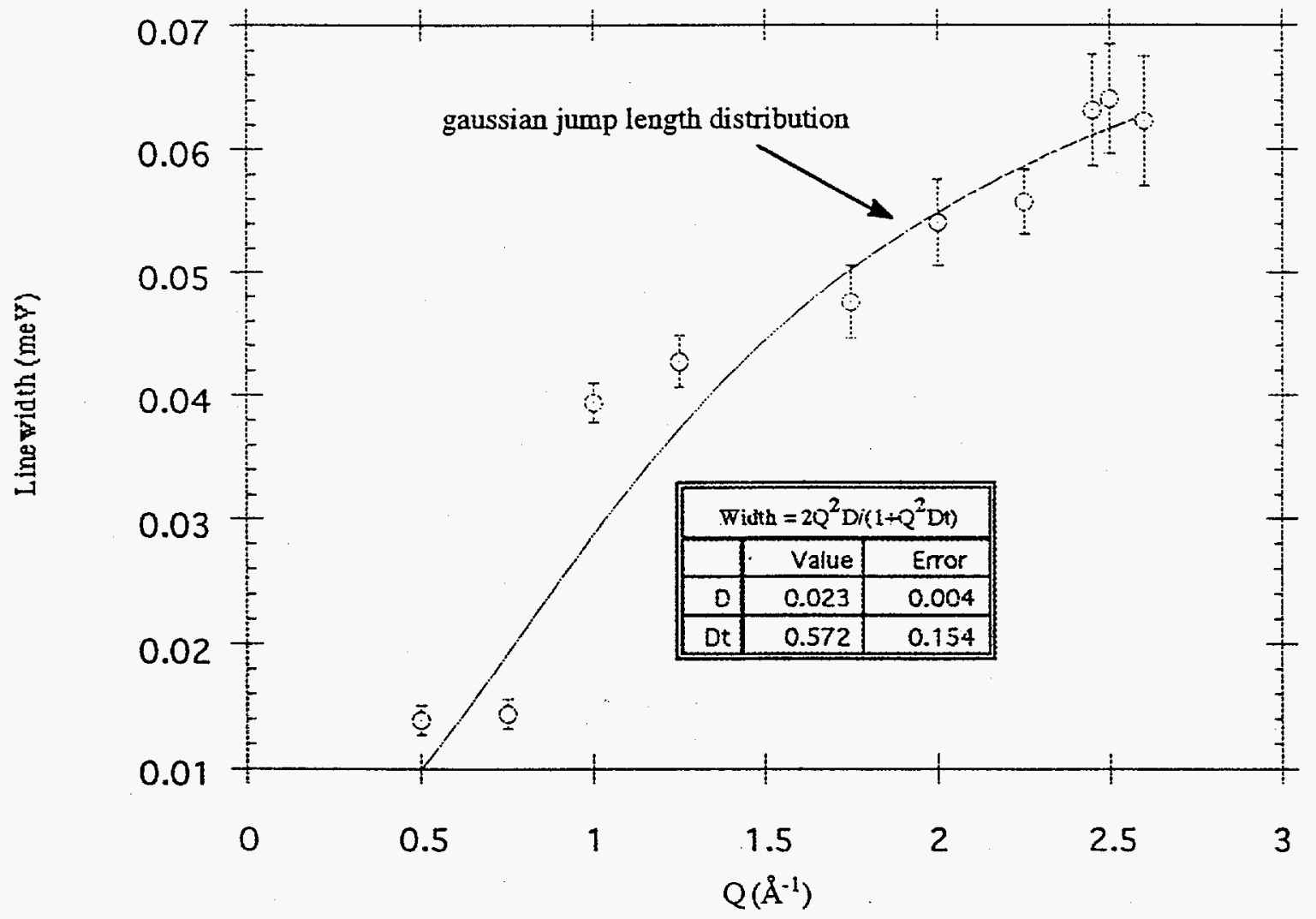




\section{6}

Fig. 10 . Spectra of protein crystals for various $Q$ at $300 K$.

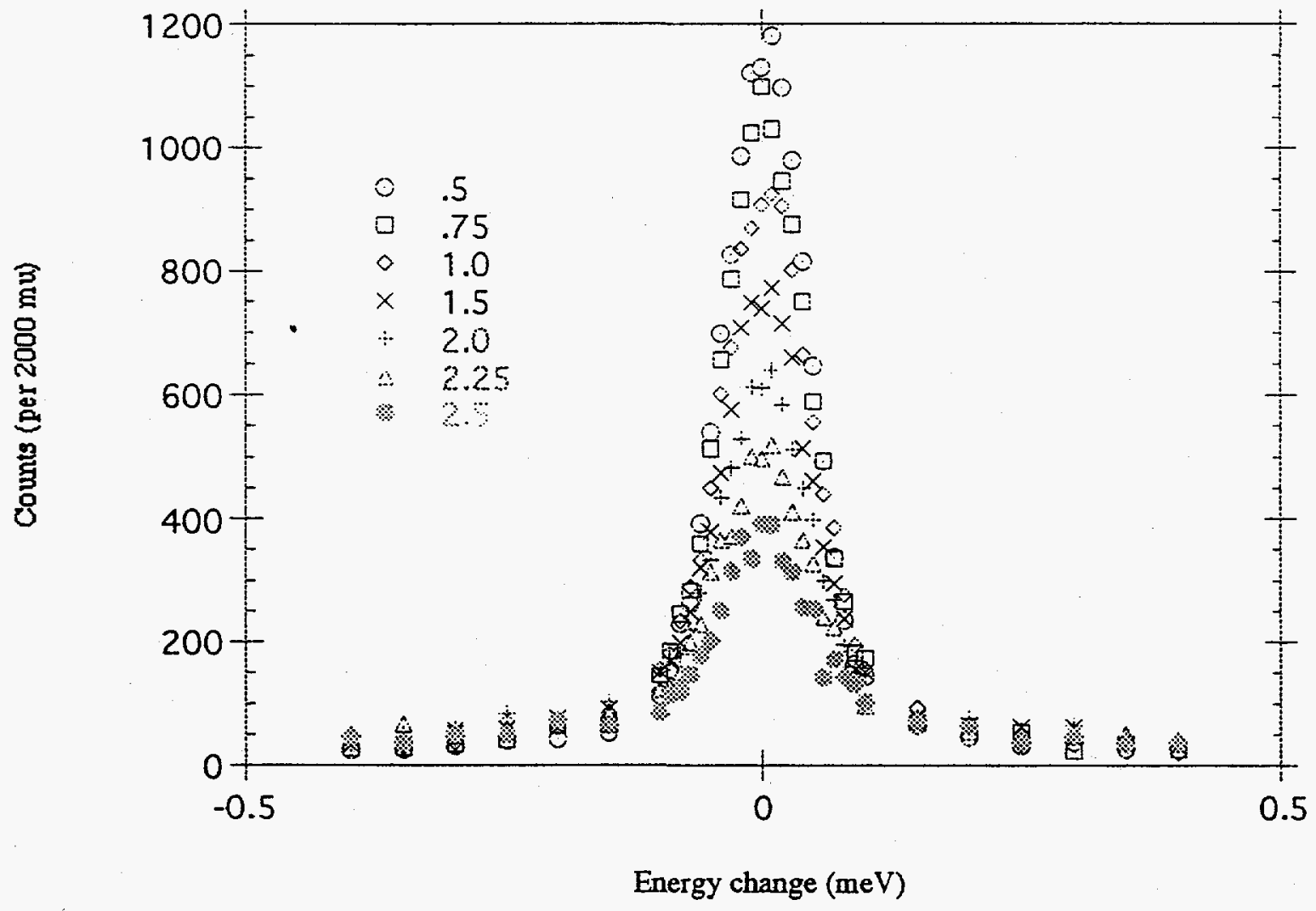


7

Fig. Y-12a. Thermal vibrations at different temperature for $\mathrm{Mb}$ in solution.

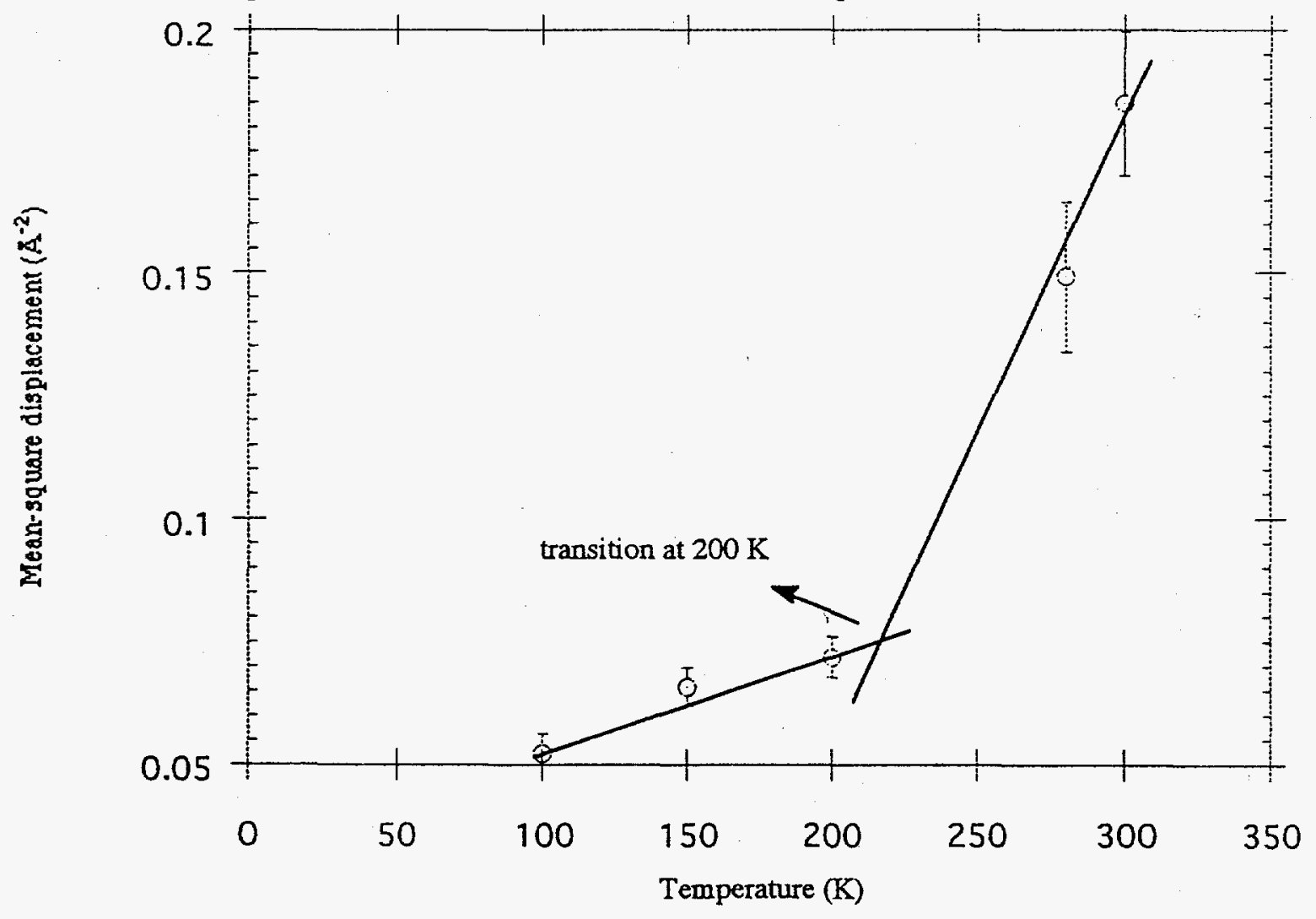

